\title{
Analysis Models for HPV-Related Pathobiology
}

\author{
Águeda Buitrago-Pérez, Jesús M. Paramio and Ramón García-Escudero \\ Molecular Oncology Unit, Dept. of Basic Research, CIEMAT, Madrid \\ Spain
}

\section{Introduction}

Human papillomaviruses (HPV) are involved in the aetiology of human carcinomas arising in different anatomical locations such as skin, anogenital region and oropharynx (Marur et al., 2010; Pfister, 2003; zur Hausen, 2002). The virus infects stratified epithelia of these locations, producing new infectious viral particles. HPV life cycle is intimately dependant of a proper squamous cell differentiation, so simple cell culture systems are unable to recapitulate essential processes for a complete virus replication. Mucosal HPVs are responsible of benign lesions and carcinomas of the anogenital region and oropharynx. There are a few types of mucosal HPVs that are present in cancers in these anatomical locations, and they are called high-risk types (mainly HPV types 16 and 18) (de Sanjose et al., 2010). Furthermore, low-risk mucosal HPV types are responsible of frequent benign lesions in the same locations (mainly HPV types 6 and 11) (zur Hausen, 2002). Although these HPV-lesions (condylomas and respiratory papillomatosis) do not evolve normally to overt tumours, they are difficult to treat.

Cervical cancer is the second leading cause of deaths by cancer in women worldwide, representing an important disease in developing countries. The vast majority of cervical carcinomas (about 85\%) are infected with high-risk HPVs, so viral infection is considered the major main etiological agent of this malignancy (de Sanjose et al., 2010). Head and neck squamous cell carcinoma (HNSCC) is the sixth most common cancer worldwide. An important proportion of human HNSCC are infected with high-risk HPV (about 20\%), especially in the oropharynx, where about $50 \%$ of the cancers have been found to harbour viral DNA (Marur et al., 2010). HNSCC is etiologically associated with tobacco use and alcohol consumption. Epidemiological and molecular studies have suggested than HPVnegative and HPV-positive tumours represent different subtypes of HNSCC with different clinical consequences. The infected HNSCC display a better clinical outcome after treatment with radio or chemotherapy.

Cutaneous HPVs, similarly to mucosal viruses, are associated to benign lesions (such as skin warts) or premalignant actinic keratosis or squamous cell carcinomas (SCC), especially in patients of the rare genodermatosis Epidermodysplasia verruciformis (EV) or in organ transplant recipients (OTRs) (Pfister, 2003). In these patient populations, the infection with certain HPV types, belonging to the beta family (beta-HPVs), is clearly associated with the appearance of those skin pathologies, mostly in sun exposed areas of the body. Although the majority of cervical carcinomas are produced by 2 major HPV types (HPV16 and 
HPV18), epidemiological studies have demonstrated that SCCs arising in papillomavirusinfected skin are associated to diverse HPV types, and that multiple infections frequently appear in a single sample (Berkhout et al., 2000; Harwood et al., 2000). Collectively these epidemiological data show that the infection with HPV is associated with a relevant number of human malignancies, and the finding of effective anti-HPV therapies represents an important medical challenge.

The most important high-risk HPV genes involved in carcinogenesis are the E6 and E7 early genes, as they are expressed in pretumoral and invasive cervical carcinomas. Importantly, a number of cellular targets for E6 and E7 have been described so far, some of which may be functionally inactivated in vivo, giving to the appearance of malignant cervical tumours. Tumour suppressors targeted by virus oncogenes are the retinoblastoma protein $(\mathrm{pRb})$ and p53, which are inhibited by high-risk HPV E7 and E6 virus oncogenes, respectively (Dyson et al., 1989; Werness et al., 1990). E7 protein from HPV16 binds directly the 3 members of the retinoblastoma protein family: pRb, p107 and p130. Upon interaction, these proteins are targeted for degradation (Boyer et al., 1996; Gonzalez et al., 2001), releasing the transcription factor complex E2F that induces the expression of genes involved in G1-S transition, thereby activating cellular proliferation. HPV16 E7 protein can also inhibit other negative regulators of the cell cycle, such as p21 cip1 thought direct binding (Funk et al., 1997; Helt et al., 2002; Jones et al., 1997). Although the virus DNA is normally maintained in the basal cells as an episome, during the malignant transformation of cervical lesions both E6 and E7 are integrated into the cellular genome (Smith et al., 1992), concomitantly with a more efficient oncogene expression. The interaction with pRb, p53 and p21 cip1 tumour suppressors, and additional targets or/and genetic alterations may eventually transform infected cells and induce the formation of invasive carcinomas. Cutaneous betaHPVs are thought to act by potentiating the harmful effects of UV radiation, for example by impairing DNA repair and apoptosis following UV-induced damage through E6 molecular activities (Akgul et al., 2005; Giampieri et al., 2004; Jackson et al., 2000; Jackson \& Storey, 2000). Mucosal high-risk HPVs could possibly act together with steroid hormone signalling and/or tobacco consumption (Moreno et al., 2002; Munoz et al., 2002). Finally, immunosupression also contributes to carcinoma progression, especially for skin SCCs.

\section{HPV analysis models}

In order to recapitulate virus life cycle towards virion production, or to analyze the phenotypical and molecular consequences of the expression of HPV genes in stratified epithelia, several models have been described. Organotypic (raft) cultures of skin where first described in 1988 to partially recapitulate the differentiation defects of human biopsies of cervical intraepithelial neoplasia (CIN) lesions, which are the precursor lesions of invasive HPV-related cervical cancers (McCance et al., 1988). The system provides an in vitro assay where primary human foreskin epithelial cells, seeded onto a collagen matrix, are forced to differentiate and reconstitute human skin (Asselineau \& Prunieras, 1984; Kopan et al., 1987). On the other hand, transgenic mouse models expressing HPV genes have demonstrated the oncogenic activities of some early viral genes, mainly E6 an E7 (Griep et al., 1993). Viral transgenes have been expressed under the control of the K14 promoter, normally expressed in the basal layer of mouse stratified epithelia (Arbeit et al., 1994). Advantages and 
disadvantages of both model systems will be described below. Furthermore, we perform a comparison of the HPV-mouse models with transgenic mice with conditional expression of the host genes normally targeted by virus oncogenes, and whose functional inactivation is essentially involved in virus carcinogenesis, such as retinoblastoma proteins or p21cip1 (targeted by E7) and p53 (targeted by E6).

\subsection{Organotypic (raft) cultures and HPV}

Raft cultures allow primary human keratinocytes (PHK) to achieve stratification and differentiation morphologically similar to foreskin (Asselineau \& Prunieras, 1984; Kopan et al., 1987). In this system, PHK cells are seeded on a dermal equivalent consisting of a porous collagen gel containing fibroblasts. At confluence, the assembly is raised to the medium-air interface. The keratinocytes stratify and exhibit a differentiated morphology, generating a living skin equivalent. This system was originally used to study the features of HPVimmortalized cell lines or cell lines obtained from cervical pathological biopsies (Blanton et al., 1991; McCance et al., 1988; Woodworth et al., 1992). These early studies demonstrated altered differentiation patterns and morphological features resembling human cervical neoplasia such as suprabasal mitosis, enlarged nuclei, abnormal mitotic figures, or koilocytosis. Later, rafts were used to produce virus particles using different strategies. Thus, Meyers et al. were able to produce virions using raft cultures of the cell line CIN-612 treated with TPA (Meyers et al., 1992). Similarly, mature particles were obtained from condyloma containing HPV11 explanted on rafts (Dollard et al., 1992).

The raft culture system has been an essential tool to analyze some of the molecular functions and consequences of the expression of E6 and E7 oncogenes from high-risk mucosal HPVs. Using retrovirally infected PHKs, it was demonstrated that E7 was able to induce DNA replication in suprabasal differentiated keratinocytes (Cheng et al., 1995), an activity directly linked to the capacity of binding retinoblastoma family or "pocket" proteins, as demonstrated by using E7 mutant proteins. Furthermore, most of the morphological features observed using HPV-cell lines where reproduced expressing E7 protein, and more clearly, with the combined expression of E6 and E7 oncogenes.

Recently, a system to produce autonomous HPV-18 genomes and high titer, mature virus particles was described using Cre-loxP-mediated recombination and organotypic cultures of PHKs (Wang et al., 2009). Interestingly, the method showed that E6 protein, and thus p53 degradation, was necessary to obtain a productive HPV program, including viral DNA amplification and production of virus capsid protein L1.

\subsection{Mouse models of HPV-mediated carcinogenesis}

Transgenic mouse models have been frequently used to analyze the molecular and phenotypic consequences of the expression of oncogenes in tumour development. Early studies demonstrated that E6 and E7 early genes from HPV16 induced tumours when the expression was targeted to the ocular lens (Griep et al., 1993), or the skin of transgenic mice (Arbeit et al., 1994; Lambert et al., 1993). These studies contributed importantly to the establishment that E6 and E7 genes are directly implicated in the carcinogenic potential of HPV16 in an animal model. Furthermore, they opened new and important research areas that have significantly contributed to the understanding of the molecular activities of both 
oncogenes in the context of HPV-associated carcinogenesis. Additionally, similar mouse models using early genes from cutaneous HPVs, associated with human skin SCC, have also helped to demonstrate their carcinogenic potential (Dong et al., 2005; Schaper et al., 2005).

Transgenic mouse containing the E6 and E7 genes from HPV16 under the control of the human keratin 14 (K14) allow expression of the virus genes in stratified epithelia, such as skin or mucosal tissues. Reproducible multi-stage progression from hyperplastic and/or dysplastic lesions to squamous cell carcinomas of the epidermis was observed in K1416E6E7 animals (Arbeit et al., 1994; Coussens et al., 1996). Concomitant with tumour progression, a disorganization of the normal differentiation was observed based of histological analysis and expression patterns of keratin markers such as keratin 5 (K5, normally expressed in basal cells), keratin 10 (K10, normally expressed in spinous cells) and filaggrin (normally expressed in granular cells). Furthermore, proliferative cells appeared ectopically in suprabasal cells and the mitotic index was augmented in premalignant and malignant skin lesions.

Herber et al reported in 1996 the first experimental evidence that the E7 protein from HPV16 is able to induce carcinogenesis in an animal model (Herber et al., 1996). Histological analysis of K14-16E7 mice demonstrated that E7 causes epidermal hyperplasia in skin, but also in mouth palate, oesophagus, forestomach and exocervix. Late in life, K14-16E7 animals develop highly differentiated and locally invasive skin carcinomas. Also, expression of E6 in K14-16E6 mice not only increased cell proliferation and induced epidermal hyperplasia, but also leads the development of skin tumours (Song et al., 1999). In contrast to the tumours derived from K14-16E7 transgenic mice, which were primarily benign, those appearing in K14-16E6 transgenic mice were mostly malignant, indicating that E6 alone not only is sufficient to induce tumour development but it also confers increased malignant potential in vivo.

The mouse models above described recapitulated in the skin the pathological features observed in human CIN lesions and cervical carcinomas. Moreover, these models demonstrate that most of these features are due to the expression of E6 and E7 HPV16 oncogenes. However, the K14-HPV16 animals did not develop spontaneous tumours in the cervix nor in the head and neck region. Importantly, Arbeit et al demonstrated that chronic estrogen administration induced cervico-vaginal squamous carcinomas in K14-16E6E7 animals (Arbeit et al., 1996). Previous epidemiological analyses already showed that the prolonged use of contraceptives, most of which contain estrogen, did double the risk of HPV neoplasia and malignancy (Brisson et al., 1994). Importantly, no control animals neither K1416E6E7 mice develop pathological neoplasias or carcinomas, demonstrating for the first time a synergism between estrogens and HPV oncogenes in cervical carcinogenesis.

Human HNSCC is associated with tobacco use, and an important proportion of tumours are HPV-infected. Strati et al demonstrated that K14-HPV16 animals, when treated with the chemical carcinogen 4-nitroquinoline 1-oxide (4NQO), increased dramatically the animal's susceptibility to HNSCC (Strati et al., 2006). 4NQO causes a spectrum of DNA damage similar to that caused by tobacco-associated carcinogens, and it induces cancers in the oral cavity in rodents when it is supplied in their drinking water. 4NQO-treated, HPV16transgenic mice developed HNSCC at a much higher frequency than no transgenic mice, and display tumours with molecular characteristics similar to the human counterparts. 
Cutaneous beta-HPVs are associated with actinic keratosis and skin SCCs in immunocompetent but mainly in immunosupressed patients, such as OTR. Some of these viruses (HPV5 and HPV8) were originally described in EV patients (Jablonska \& Majewski, 1994; Lutzner et al., 1984), but these and other beta-HPVs have been generally associated to human skin cancer. As for high-risk mucosal HPVs, transgenic mouse models have been generated in order to analyze the carcinogenic properties of cutaneous HPVs. Schaper et al demonstrated that the early region of HPV8, containing the E2, E6 and E7 genes, was able to induce single or multifocal tumours in $91 \%$ of K14-HPV8 animals and skin carcinomas in $6 \%$ of all examined mice (Schaper et al., 2005). This report was the first experimental proof of the carcinogenic potential of an EV-associated HPV-type in vivo. A few months later, Dong et al described skin hyperproliferation and susceptibility to chemical carcinogenesis in transgenic mice expressing the E6 and E7 genes of HPV38 (another EV-associated beta-HPV) under the control of the bovine homolog of human keratin 10 (K10) promoter (Dong et al., 2005). Although transgenic K10-HPV38 mice did not develop spontaneous tumours, twostage carcinogenesis protocols led to a high incidence of papillomas, keratoacanthomas and SCC in the transgenic mouse skin compared with nontransgenic control mice. These results showed HPV38 E6 and E7 display transforming properties in vivo.

\section{Synergism and individual contribution of E6 and E7 oncogenes to HPV16- induced carcinogenesis}

K14-HPV16 transgenic animals have been valuable tools to demonstrate the essential role of virus E6 and E7 oncogenes in stratified epithelia carcinogenesis. The individual contribution of both genes as well as the synergism has been studied for carcinoma models in skin, cervix and head and neck. Thus, E6 is the most important oncogene in skin cancer as the tumours arising are more malignant than those that appeared in K14-16E7 animals (Song et al., 2000; Song et al., 1999) (Fig. 1). An analysis including chemical carcinogenesis with DMBA/TPA demonstrated that E6 acts weakly at the promotion stage of carcinogenesis in the formation of benign tumours, but strongly at the progression stage, which involves the malignant conversion of these benign tumours (Song et al., 1999). In contrast, E7 primarily affected the promotion stage of carcinogenesis. These results provide direct evidence that E6 and E7 contribute differently to carcinogenesis; E7 promotes the formation of benign tumours, and E6 acts primarily to accelerate progression of these benign tumours to the malignant stage. Consistent with this model, the authors found that E6 and E7 cooperated in inducing tumour formation in mice expressing both oncogenes.

In the case of estrogen induced cervical carcinomas in K14-HPV16 animals, E7 was found to be the most important oncogene (Fig. 1). Importantly, although p53 levels were eliminated in cervical epithelium of estrogen treated K14-16E6 mice, neither neoplasia nor cancer was observed. Again, a synergism was observed with both E6 and E7 oncogenes, giving rise to large, extensively invasive cancers (Riley et al., 2003).

Similarly, the individual contribution of each virus oncogene was analyzed in the HNSCC model of K14-HPV16 animals. The results demonstrated that E7 is the major transforming oncogene in HPV-associated HNSCC, whereas E6 is more likely to play a secondary role in contributing to later stages of carcinogenesis (Strati \& Lambert, 2007) (Fig. 1). As described above for skin and cervical carcinogenesis, again both E6 and E7 oncogenes act 
synergistically to produce a higher grade of disease and slightly increased tumour multiplicity.

\section{Transgenic mouse models of HPV16-carcinogenesis}

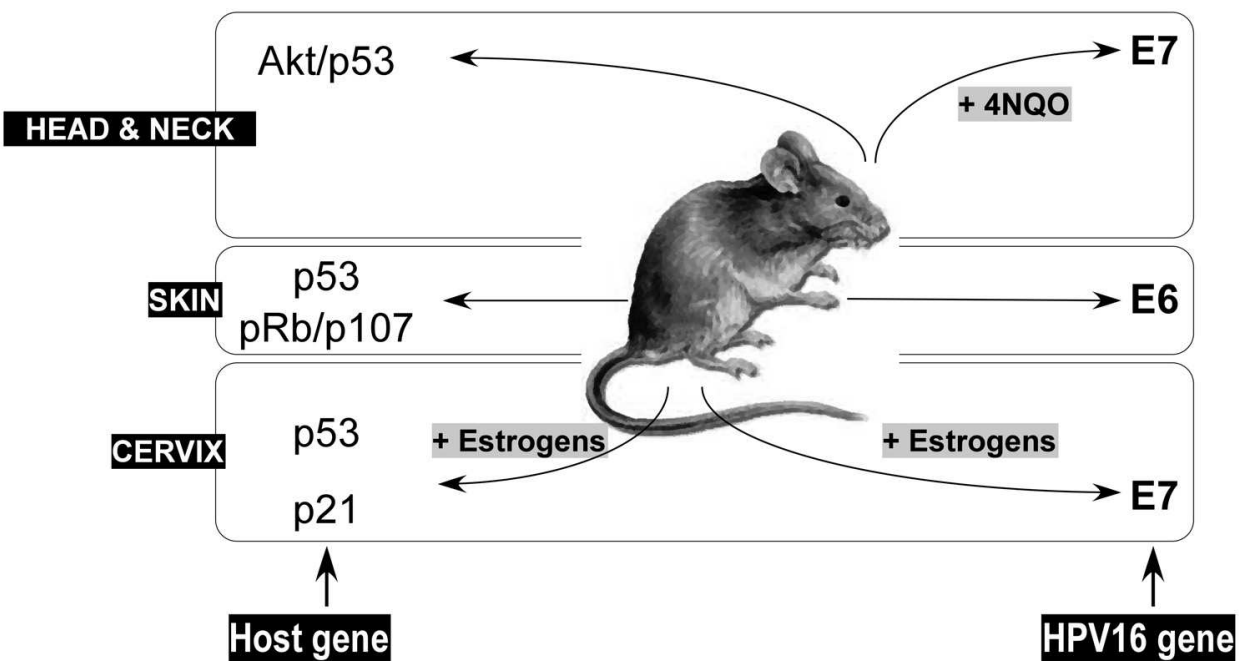

Fig. 1. Transgenic mouse models of HPV16-carcinogenesis. K14-HPV16 mouse models develop carcinomas in the head and neck region, skin, and cervix. While spontaneous tumors arise in the skin, HNSCCs appear in cooperation with the 4 NQO carcinogen, and cervical carcinomas in cooperation with estrogens. Characterization of K14-16E6, K14-16E7, and K14-16E6E7 mice have demonstrated that E6 is the main virus oncogene in skin SCC, and E7 in HNSCC and cervical carcinoma. On the other hand, transgenic animals with deletion in HPV-cellular targets have demonstrated that p53 or pRb/p107 are major tumor supressors in skin. In the presence of estrogens, deletions of p53 or p21 give rise to carcinogenesis in the mouse cervix. Finally, continuous activation of Akt in the absence of p53 induces spontaneous carcinomas in the head and neck region. For references, see text.

\section{Role of cellular targets of HPV oncogenes in carcinogenesis}

A number of cellular proteins are targets of HPV oncogenes. However, the real contribution of these targets in human pathology during the carcinogenesis process is not completely understood. Compelling evidences have demonstrated that p53 and pRb are the major cellular targets of high-risk HPV E6 and E7 oncogenes, respectively. The role of both cellular proteins as tumour suppressors in the vast majority of human cancer has been fully established. However, the importance of their inhibition during the carcinogenesis associated to HPV-infection has not been completely characterized. K14-HPV16 models have demonstrated that E7 is the main oncogene in HNSCC and cervical cancer, but in skin tumour formation only participated at the initiation step. Interestingly, both E6 and E7 oncogenes act synergistically to induce tumour formation and malignancy in the three types of cancer. 


\subsection{Skin cancer}

In relation with skin cancer, mouse models with conditional somatic deletion of $\mathrm{pRb}$ and/or p53 have been characterized. The elimination of $\mathrm{pRb}$ in the epidermis of transgenic mice using the Cre-lox system (K14Cre;RbloxP/loxP) produces hyperplasia, altered differentiation and ectopic suprabasal proliferation in the skin (Balsitis et al., 2003; Ruiz et al., 2004) but not spontaneous tumours. This phenotype resembles the epidermal histological features of K1416E7 animals, which is in line with the inactivation of pRb due to E7 expression (Balsitis et al., 2003). However, when both E7 was expressed and Rb was deleted in the same tissue, increased hyperplasia and dysplasia were observed, suggesting that E7 possesses pRbindependent effects. E7 protein from HPV16 is also able to inactivate the other two members of the retinoblastoma family, p107 and p130. It is tempting to speculate that the epidermal phenotype observed in K14-16E7 animals could be partially due to inactivation of $\mathrm{pRb}$, but also of p107 and/or p130. Interestingly, we have previously demonstrated that the absence of p107 alleles in K14Cre;RbloxP/loxP mice (K14Cre;RbloxP/loxP;p107-/-) increased the $\mathrm{K} 14 \mathrm{Cre} ; \mathrm{Rb}$ loxP/loxP epidermal phenotype with augmented hyperplasia, proliferation and altered differentiation (Lara et al., 2008a; Ruiz et al., 2004), which was associated to a equivalent increase in the expression of $\mathrm{pRb}$-dependent gene expression program (Lara et al., 2008a; Ruiz et al., 2004). However, we were not able to observe an increase in the $\mathrm{K} 14 \mathrm{Cre}$;Rb $b^{\text {loxP/loxP }}$ epidermal phenotype in $\mathrm{K} 14 \mathrm{Cre} ; \mathrm{Rb}$ loxP/loxP;p130-/- animals, suggesting that p107 (and not p130) could functionally compensate some of the pRb-dependent functions. Although K14Cre;RbloxP/loxP;p107-/- animals died soon after birth, thus precluding analysis of phenotype in adult animals, we were able to analyze the consequences of somatic inactivation of both $\mathrm{pRb}$ and $\mathrm{p} 107$ by transplanting K14Cre;RbloxP/loxP;p107-/- neonatal skin onto immunodeficient NOD/Scid mice. The grafted transgenic skin develops well differentiated SCC, characterized by a reduced apoptosis possibly due to a defective p53 pathway (Lara et al., 2008b) (Fig. 1). Moreover, the K14Cre;RbloxP/loxP;p130-/- mice do not develop spontaneous tumours with age. Altogether, these data suggest that the spontaneous skin SCCs that appear in K14-16E7 animals could be due to simultaneous inactivation of pRb and p107 in the epidermis, although inactivation of all three pocket proteins cannot be discarded. In this regard, the elimination of p130 and p107 also produces severe skin defects, indicating that these two proteins also exert overlapping functions that cannot be carried out by pRb in epidermis (Ruiz et al., 2003).

In relation with p53, others and we have demonstrated that p53 is a major tumour suppressor in skin (Jonkers et al., 2001; Martinez-Cruz et al., 2008) (Fig. 1). When $\mathrm{K} 14 \mathrm{Cre}$; $\mathrm{Rb}$ loxP/loxP animals were treated with the DMBA/TPA chemical carcinogenesis protocol, they display reduced number and smaller tumours than the control, RbloxP/loxP littermates. However, these tumours also displayed a more malignant phenotype partially due to the absence of p53 (Ruiz et al., 2005). These results strongly suggested that p53, in the absence of $\mathrm{pRb}$, had compensatory tumour suppressor activities. The essential role of p53 as a tumour suppressor in skin was fully demonstrated when analyzing K14Cre;p53loxP/loxP and $\mathrm{K} 14 \mathrm{Cre}$; RbloxP/loxP;p53loxP/loxP animals. Both transgenic animals developed spontaneous tumours in the skin with full penetrance, although the onset was earlier in the case of double conditional knock-out (Martinez-Cruz et al., 2008). No major differences were observed in overt tumours, which were characterized as moderately differentiated or undifferentiated, locally aggressive and metastatic. Interestingly, the gene expression pattern of tumours from 
both mouse genotypes resembles that of human tumours with mutations in p53 (GarciaEscudero et al., 2010). As previously described, K14-16E6 mice develop spontaneous tumours with a more aggressive behaviour than K14-16E7 tumours. Altogether the results would indicate that E6 is the most important HPV oncogene in skin as it is able to inhibit p53, a predominant tumour suppressor in skin.

Finally, p53-independent activities have been described for E6 in skin. Numerous cellular proteins interact with E6. One group of proteins, the PDZ partners (including hDLG, hSCRIBBLE, MUPP1, and MAGI) interact to the C-terminal four amino acids of E6 through their PDZ domains, leading to their degradation. Additionally, E6's binding to PDZ proteins may explain the E6 ability to transform cells in tissue culture and to confer tumorigenicity to cells in xenograft experiments (Kiyono et al., 1997). Mice with a mutant of E6 lacking the last six amino acids of its carboxyl terminus (K14-16E6 $6^{\Lambda_{146-151}}$ ) were generated, and allowed to demonstrate that the ability of E6 to bind PDZ domain partners is necessary for E6 to confer epithelial hyperproliferation in vivo. The $\mathrm{K} 14-16 \mathrm{E} 6^{\Delta}{ }^{146-151}$ mice exhibit a radiation response similar to that of the K14-16E6 mice, demonstrating that this protein, as predicted, retained an ability to inactivate p53.

\subsection{Cervical cancer}

Using K14-HPV16 transgenic mice and estrogen treatment, mouse models have demonstrated an essential contribution of the E7 oncogene in cervical cancer. Furthermore, repression of the E7 oncogene efficiently cleared already established carcinomas. In order to elucidate the role of $\mathrm{pRb}$ in suppression of cervical cancer, $\mathrm{K} 14 \mathrm{Cre}$; $\mathrm{Rb} \operatorname{loxP} / \operatorname{loxP}$ animal were hormone treated. The results demonstrated no carcinoma formation, suggesting that $\mathrm{pRb}-$ independent activities are exerted by E7. Further evidence was provided by the generation of $\mathrm{Rb}^{\Delta} \mathrm{L} /{ }_{\mathrm{L}} \mathrm{mice}$. This gene construct bears three alanine mutations in $\mathrm{pRb}$ that interact with E7, thereby producing a mutant pRb protein that fails to bind E7 (Lee et al., 1998). On the other hand $\mathrm{pRb}^{\Delta} \mathrm{L}$ retains the ability to bind $\mathrm{E} 2 \mathrm{Fs}$, induces $\mathrm{G} 1$ arrest in $\mathrm{pRb}$-negative SAOS2 cells, and is phosphorylated and inactivated by cyclin D/cdk4 complexes similarly to wt $\mathrm{pRb}$ (Dick et al., 2000). $\mathrm{pRb}^{\Lambda_{\mathrm{L}}}$ also represses gene expression from E2F-responsive promoter constructs, although incrementally less effectively than wt $\mathrm{pRb}$. On the other hand, $\mathrm{pRb} \mathrm{b}^{\Delta_{\mathrm{L}}}$ fails to bind cellular $\mathrm{LxCxE}$ motif-containing proteins, and $\mathrm{pRb}^{{ }_{\mathrm{L}}}$-induced $\mathrm{G} 1$ arrest cannot be reversed by expression of HPV-16 or HPV-18 E7 (Dick et al., 2000; Isaac et al., 2006). $\mathrm{K} 14 \mathrm{E} 7 \mathrm{Rb}^{\Delta_{\mathrm{L}} /{ }^{\Delta} \mathrm{L}}$ mice were used to analyze cervical carcinoma formation. The development of spontaneous tumours indicates, again, that other molecular activities of E7, independent of $\mathrm{pRb}$, make critical contributions to cervical carcinogenesis. Although the role in cervical carcinogenesis has not been tested, it is possible that p107 may act as a tumour suppressor in this tissue in the absence of $\mathrm{pRb}$, as we have been demonstrated for skin SCC (Lara et al., $2008 \mathrm{~b})$. However, we cannot discard an essential role of other tumour suppressors, such as p130 or p21 Cip1, also targeted by high-risk E7.

Using knock-out animals, Shin et al described that cervical disease was significantly increased in p21 -/- mice compared with p21+/+ mice, showing that p21Cip1 can function as a tumour suppressor in this tissue (Shin et al., 2009) (Fig. 1). Importantly, the induction of cervical cancers by E7 was not increased in the absence of p21Cip1, arguing against the hypothesis that the ability of E7 to inhibit p21 $^{\text {Cip }}{ }^{1}$ contributes to carcinogenesis. However, 
cervical carcinogenesis in mice expressing a mutant form of HPV-16 E7, E7CVQ, which cannot inactivate p21Cip1, was reduced when compared with that in K14-16E7 mice. Nonetheless, K14-16E7CVQ mice still displayed augmented levels of cervical carcinogenesis compared with non-transgenic mice, indicating that activities of E7, besides its capacity to

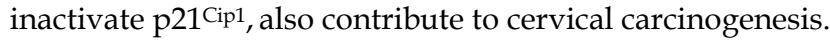

The interaction of E6 with many cellular proteins, including p53, leads to their destabilization. This property is mediated, at least in part, through the ability of E6 to recruit the ubiquitin ligase E6-associated protein (E6AP) into complexes with these cellular proteins, resulting in their ubiquitin-mediated degradation by the proteasome pathway. Shai et al addressed the requirement for E6AP in mediating acute and oncogenic phenotypes of E6, including induction of epithelial hyperplasia, abrogation of DNA damage response, and induction of cervical cancer (Shai et al., 2010). Loss of E6AP had no discernible effect on the ability of E6 to induce hyperplasia or abrogate DNA damage responses. Nevertheless, in cervical carcinogenesis studies, there was a complete loss of the oncogenic potential of E6 in E6AP-null mice. Thus, E6AP is absolutely required for E6 to cause cervical cancer. However, when K14Cre;p53loxP/loxP were treated with estrogen, nearly all mice developed cervical cancer, in sharp contrast to its complete absence in treated K1416E6; p53loxP/loxP mice, indicating that HPV16 E6 must only partially inactivate p53 (Shai et al., 2008) (Fig. 1). p53-independent activities of E6 also contributed to carcinogenesis, but these activities were manifested only in the presence of the HPV16 E7 oncogene.

\subsection{Head and neck squamous cell carcinoma}

Individual and synergistic contributions of E6 and E7 oncogenes were also determined in a mouse model for human HNSCC where K14-HPV16 animals are treated with the 4NQO carcinogen. The results showed that E7 is the major oncogene (Strati \& Lambert, 2007) in HPV-associated HNSCC, whereas E6 is more likely to play a secondary role in contributing to later stages of carcinogenesis. Mutations in p53 have been described in about $50 \%$ of human HNSCC, demonstrating that the inactivation of the p53 pathway is a highly relevant molecular event for carcinogenesis in this region. In the case of HPV-infected HNSCC, the frequency of mutations is very low as E6 would be able to inhibit p53 function. However, we have recently described a mouse model where an active form of the Akt1 kinase (myrAkt) expressed in stratified epithelia under the control of the keratin 5 (K5) promoter is able, in the absence of p53 (K5myrAkt;K14Cre;p53loxP/loxP), to induce HNSCC (Moral et al., 2009) (Fig. 1). This mouse model recapitulates most of the pathological features of human HNSCC, such as local lymph node metastasis. The results corroborate the epidemiological studies about the role of p53 in human HNSCC, as K5myrAkt animals display significant reduction in the development of overt tumours although they display high number of pretumoral lesions and also display increased susceptibility to chemical carcinogenesis protocols (Moral et al., 2009; Segrelles et al., 2007). Possibly, the treatment with 4NQO induces mutations that inactivate the p53 pathway, thus explaining the secondary role of E6 in the HPV-associated HNSCC mouse model. Alternatively, the E6 protein may not completely inactivate p53 in head and neck, as suggested before in the case of cervical cancer (Shai et al., 2008).

Furthermore, a conditional deletion of $\mathrm{pRb}$ did not recapitulate all E7-mediated cancer phenotypes in HNSCC (Strati \& Lambert, 2007). As in the case of cervical cancer mouse 
models, the results highlight the importance of $\mathrm{pRb}$-independent functions of E7 in head and neck carcinogenesis, although do not preclude an important role for the E7-pRb interaction.

\section{Analysis of preclinical therapies in the mouse cervical cancer model}

Interfering with the expression of E7 in HPV-positive cell lines derived from human cervical cancers inhibits their ability to proliferate, indicating that the expression of E7 is important in maintaining the transformed phenotype in vitro. Accordingly, in vivo experiments using transgenic mice with inducible repression of the E7 oncogene of HPV16 demonstrated that E7 expression in estrogen induced cervical carcinomas is necessary to maintain established tumours and high-grade cervical dysplasia (Jabbar et al., 2009). The results obtained suggest that E7 is a relevant target nor only for anticancer therapy but also for the treatment of HPVpositive dysplastic cervical lesions.

Mouse models of human cancer are necessary tools to understand basic processes of carcinogenesis in a living organism, but also as tools to analyze preclinical therapies. In this sense, Chung et al have recently described that estrogen receptor antagonists are effective preventive and therapeutic drugs in mouse models of cervical cancer (Chung \& Lambert, 2009). The authors demonstrated that ICI 182, 780 (a complete ER antagonist) and raloxifene (a selective ER modulator) efficiently clear cancer and precursor lesions in both the cervix and the vagina. Importantly, these findings suggest that ER antagonists could help to control this gynecological disease of the women lower reproductive tract.

\section{Conclusion}

Analysis models of HPV based on organotypic cultures of human skin or transgenic mice have helped to understand the function and carcinogenesis role of HPV oncogenes. Thus, the role of E6 and E7 as major oncogenes has been established and the contribution of each of them, as well other cofactors, has been analyzed. Human cancers associated with HPVinfection are multifactorial diseases, in which genetic predisposition, tobacco or estrogen consumption, radiation exposure, or immunosuppression are factors that could contribute to its appearance or development. In K14-HPV16 animal models, E7 is the most important virus oncogene for cervical cancer and HNSCC. Although pRb is the major E7 target, there are $\mathrm{pRb}$-independent functions for E7-mediated carcinogenesis. In the case of skin SCC, E6 gives rise to more malignant tumours that E7, which coincides with a role of p53 as an important tumour suppressor in K14Cre;p53loxP/loxP animals. Furthermore, these p53 mutant mice develop aggressive tumours in skin and cervical cancer models with high penetrance, showing that E6 from HPV16 is not able to completely inactivate p53. On the other hand, transgenic mice have helped to demonstrate tumorigenic activity of cutaneous beta-HPV oncogenes in vivo, for the first time.

Human papillomaviruses are infectious agents with clinical importance. Although already developed vaccines are a preventive treatment against non-malignant and malignant virusassociated lesions, new HPV therapies are necessary for already infected people. In this sense, raft cultures have the advantage that they are done with PHKs (the proper cellular target and species of HPV-infection), but the disadvantage that the time window to test therapies is limited to a few days. On the other hand, mouse models allow testing long-term 
effects of new possible anti-HPV treatments in a living organism, but the differences between mouse and human species must to be taken into account. Future models, able to bypass these drawbacks must be developed in the future for a better success in preclinical analysis, thus delivering new effective treatments to HPV-pathologies in the future.

\section{Acknowledgments}

Grant support: Ministerio de Ciencia e Innovación (MICINN) grant SAF2008-0121, Comunidad Autónoma de Madrid Oncocycle Program Grant S2006/BIO-0232, Ministerio de Sanidad y Consumo grant ISCIII-RETIC RD06/0020/0029 and from Fundación Sandra Ibarra Para la Investigación del Cáncer de Mama.

\section{References}

Akgul, B., Lemme, W., Garcia-Escudero, R., Storey, A. \& Pfister, H. J. (2005). UV-B irradiation stimulates the promoter activity of the high-risk, cutaneous human papillomavirus 5 and 8 in primary keratinocytes. Arch Virol 150(1), 145-51.

Arbeit, J. M., Howley, P. M. \& Hanahan, D. (1996). Chronic estrogen-induced cervical and vaginal squamous carcinogenesis in human papillomavirus type 16 transgenic mice. Proc Natl Acad Sci U S A 93(7), 2930-5.

Arbeit, J. M., Munger, K., Howley, P. M. \& Hanahan, D. (1994). Progressive squamous epithelial neoplasia in K14-human papillomavirus type 16 transgenic mice. J Virol 68(7), 4358-68.

Asselineau, D. \& Prunieras, M. (1984). Reconstruction of 'simplified' skin: control of fabrication. Br J Dermatol 111 Suppl 27, 219-22.

Balsitis, S. J., Sage, J., Duensing, S., Munger, K., Jacks, T. \& Lambert, P. F. (2003). Recapitulation of the effects of the human papillomavirus type 16 E7 oncogene on mouse epithelium by somatic $\mathrm{Rb}$ deletion and detection of $\mathrm{pRb}$-independent effects of E7 in vivo. Mol Cell Biol 23(24), 9094-103.

Berkhout, R. J., Bouwes Bavinck, J. N. \& ter Schegget, J. (2000). Persistence of human papillomavirus DNA in benign and (pre)malignant skin lesions from renal transplant recipients. J Clin Microbiol 38(6), 2087-96.

Blanton, R. A., Perez-Reyes, N., Merrick, D. T. \& McDougall, J. K. (1991). Epithelial cells immortalized by human papillomaviruses have premalignant characteristics in organotypic culture. Am J Pathol 138(3), 673-85.

Boyer, S. N., Wazer, D. E. \& Band, V. (1996). E7 protein of human papilloma virus-16 induces degradation of retinoblastoma protein through the ubiquitin-proteasome pathway. Cancer Res 56(20), 4620-4.

Brisson, J., Morin, C., Fortier, M., Roy, M., Bouchard, C., Leclerc, J., Christen, A., Guimont, C., Penault, F. \& Meisels, A. (1994). Risk factors for cervical intraepithelial neoplasia: differences between low- and high-grade lesions. Am J Epidemiol 140(8), 700-10.

Cheng, S., Schmidt-Grimminger, D. C., Murant, T., Broker, T. R. \& Chow, L. T. (1995). Differentiation-dependent up-regulation of the human papillomavirus E7 gene reactivates cellular DNA replication in suprabasal differentiated keratinocytes. Genes Dev 9(19), 2335-49. 
Chung, S. H. \& Lambert, P. F. (2009). Prevention and treatment of cervical cancer in mice using estrogen receptor antagonists. Proc Natl Acad Sci U S A 106(46), 19467-72.

Coussens, L. M., Hanahan, D. \& Arbeit, J. M. (1996). Genetic predisposition and parameters of malignant progression in K14-HPV16 transgenic mice. Am J Pathol 149(6), 1899917. de Sanjose, S., Quint, W. G., Alemany, L., Geraets, D. T., Klaustermeier, J. E., Lloveras, B., Tous, S., Felix, A., Bravo, L. E., Shin, H. R., Vallejos, C. S., de Ruiz, P. A., Lima, M. A., Guimera, N., Clavero, O., Alejo, M., Llombart-Bosch, A., ChengYang, C., Tatti, S. A., Kasamatsu, E., Iljazovic, E., Odida, M., Prado, R., Seoud, M., Grce, M., Usubutun, A., Jain, A., Suarez, G. A., Lombardi, L. E., Banjo, A., Menendez, C., Domingo, E. J., Velasco, J., Nessa, A., Chichareon, S. C., Qiao, Y. L., Lerma, E., Garland, S. M., Sasagawa, T., Ferrera, A., Hammouda, D., Mariani, L., Pelayo, A., Steiner, I., Oliva, E., Meijer, C. J., Al-Jassar, W. F., Cruz, E., Wright, T. C., Puras, A., Llave, C. L., Tzardi, M., Agorastos, T., Garcia-Barriola, V., Clavel, C., Ordi, J., Andujar, M., Castellsague, X., Sanchez, G. I., Nowakowski, A. M., Bornstein, J., Munoz, N. \& Bosch, F. X. (2010). Human papillomavirus genotype attribution in invasive cervical cancer: a retrospective cross-sectional worldwide study. Lancet Oncol 11(11), 1048-56.

Dick, F. A., Sailhamer, E. \& Dyson, N. J. (2000). Mutagenesis of the pRB pocket reveals that cell cycle arrest functions are separable from binding to viral oncoproteins. Mol Cell Biol 20(10), 3715-27.

Dollard, S. C., Wilson, J. L., Demeter, L. M., Bonnez, W., Reichman, R. C., Broker, T. R. \& Chow, L. T. (1992). Production of human papillomavirus and modulation of the infectious program in epithelial raft cultures. OFF. Genes Dev 6(7), 1131-42.

Dong, W., Kloz, U., Accardi, R., Caldeira, S., Tong, W. M., Wang, Z. Q., Jansen, L., Durst, M., Sylla, B. S., Gissmann, L. \& Tommasino, M. (2005). Skin hyperproliferation and susceptibility to chemical carcinogenesis in transgenic mice expressing E6 and E7 of human papillomavirus type 38. J Virol 79(23), 14899-908.

Dyson, N., Howley, P. M., Munger, K. \& Harlow, E. (1989). The human papilloma virus-16 E7 oncoprotein is able to bind to the retinoblastoma gene product. Science 243(4893), 934-7.

Funk, J. O., Waga, S., Harry, J. B., Espling, E., Stillman, B. \& Galloway, D. A. (1997). Inhibition of CDK activity and PCNA-dependent DNA replication by p21 is blocked by interaction with the HPV-16 E7 oncoprotein. Genes Dev 11(16), 2090100.

Garcia-Escudero, R., Martinez-Cruz, A. B., Santos, M., Lorz, C., Segrelles, C., Garaulet, G., Saiz-Ladera, C., Costa, C., Buitrago-Perez, A., Duenas, M. \& Paramio, J. M. (2010). Gene expression profiling of mouse p53-deficient epidermal carcinoma defines molecular determinants of human cancer malignancy. Mol Cancer 9, 193.

Giampieri, S., Garcia-Escudero, R., Green, J. \& Storey, A. (2004). Human papillomavirus type 77 E6 protein selectively inhibits p53-dependent transcription of proapoptotic genes following UV-B irradiation. Oncogene 23(34), 5864-70.

Gonzalez, S. L., Stremlau, M., He, X., Basile, J. R. \& Munger, K. (2001). Degradation of the retinoblastoma tumor suppressor by the human papillomavirus type 16 E7 oncoprotein is important for functional inactivation and is separable from proteasomal degradation of E7. J Virol 75(16), 7583-91. 
Griep, A. E., Herber, R., Jeon, S., Lohse, J. K., Dubielzig, R. R. \& Lambert, P. F. (1993). Tumorigenicity by human papillomavirus type 16 E6 and E7 in transgenic mice correlates with alterations in epithelial cell growth and differentiation. J Virol 67(3), 1373-84.

Harwood, C. A., Surentheran, T., McGregor, J. M., Spink, P. J., Leigh, I. M., Breuer, J. \& Proby, C. M. (2000). Human papillomavirus infection and non-melanoma skin cancer in immunosuppressed and immunocompetent individuals. J Med Virol 61(3), 289-97.

Helt, A. M., Funk, J. O. \& Galloway, D. A. (2002). Inactivation of both the retinoblastoma tumor suppressor and p21 by the human papillomavirus type 16 E7 oncoprotein is necessary to inhibit cell cycle arrest in human epithelial cells. J Virol 76(20), 1055968.

Herber, R., Liem, A., Pitot, H. \& Lambert, P. F. (1996). Squamous epithelial hyperplasia and carcinoma in mice transgenic for the human papillomavirus type 16 E7 oncogene. J Virol 70(3), 1873-81.

Isaac, C. E., Francis, S. M., Martens, A. L., Julian, L. M., Seifried, L. A., Erdmann, N., Binne, U. K., Harrington, L., Sicinski, P., Berube, N. G., Dyson, N. J. \& Dick, F. A. (2006). The retinoblastoma protein regulates pericentric heterochromatin. Mol Cell Biol 26(9), 3659-71.

Jabbar, S. F., Abrams, L., Glick, A. \& Lambert, P. F. (2009). Persistence of high-grade cervical dysplasia and cervical cancer requires the continuous expression of the human papillomavirus type 16 E7 oncogene. Cancer Res 69(10), 4407-14.

Jablonska, S. \& Majewski, S. (1994). Epidermodysplasia verruciformis: immunological and clinical aspects. Curr Top Microbiol Immunol 186, 157-75.

Jackson, S., Harwood, C., Thomas, M., Banks, L. \& Storey, A. (2000). Role of Bak in UVinduced apoptosis in skin cancer and abrogation by HPV E6 proteins. Genes Dev 14(23), 3065-73.

Jackson, S. \& Storey, A. (2000). E6 proteins from diverse cutaneous HPV types inhibit apoptosis in response to UV damage. Oncogene 19(4), 592-8.

Jones, D. L., Alani, R. M. \& Munger, K. (1997). The human papillomavirus E7 oncoprotein can uncouple cellular differentiation and proliferation in human keratinocytes by abrogating p21Cip1-mediated inhibition of cdk2. Genes Dev 11(16), 2101-11.

Jonkers, J., Meuwissen, R., van der Gulden, H., Peterse, H., van der Valk, M. \& Berns, A. (2001). Synergistic tumor suppressor activity of BRCA2 and p53 in a conditional mouse model for breast cancer. Nat Genet 29(4), 418-25.

Kiyono, T., Hiraiwa, A., Fujita, M., Hayashi, Y., Akiyama, T. \& Ishibashi, M. (1997). Binding of high-risk human papillomavirus E6 oncoproteins to the human homologue of the Drosophila discs large tumor suppressor protein. Proc Natl Acad Sci U S A 94(21), 11612-6.

Kopan, R., Traska, G. \& Fuchs, E. (1987). Retinoids as important regulators of terminal differentiation: examining keratin expression in individual epidermal cells at various stages of keratinization. J Cell Biol 105(1), 427-40.

Lambert, P. F., Pan, H., Pitot, H. C., Liem, A., Jackson, M. \& Griep, A. E. (1993). Epidermal cancer associated with expression of human papillomavirus type 16 E6 and E7 oncogenes in the skin of transgenic mice. Proc Natl Acad Sci U S A 90(12), 5583-7. 
Lara, M. F., Garcia-Escudero, R., Ruiz, S., Santos, M., Moral, M., Martinez-Cruz, A. B., Segrelles, C., Lorz, C. \& Paramio, J. M. (2008a). Gene profiling approaches help to define the specific functions of retinoblastoma family in epidermis. Mol Carcinog 47(3), 209-21.

Lara, M. F., Santos, M., Ruiz, S., Segrelles, C., Moral, M., Martinez-Cruz, A. B., Hernandez, P., Martinez-Palacio, J., Lorz, C., Garcia-Escudero, R. \& Paramio, J. M. (2008b). p107 acts as a tumor suppressor in pRb-deficient epidermis. Mol Carcinog 47(2), 105-13.

Lee, J. O., Russo, A. A. \& Pavletich, N. P. (1998). Structure of the retinoblastoma tumoursuppressor pocket domain bound to a peptide from HPV E7. Nature 391(6670), 85965.

Lutzner, M. A., Blanchet-Bardon, C. \& Orth, G. (1984). Clinical observations, virologic studies, and treatment trials in patients with epidermodysplasia verruciformis, a disease induced by specific human papillomaviruses. J Invest Dermatol 83(1 Suppl), $18 \mathrm{~s}-25 \mathrm{~s}$.

Martinez-Cruz, A. B., Santos, M., Lara, M. F., Segrelles, C., Ruiz, S., Moral, M., Lorz, C., Garcia-Escudero, R. \& Paramio, J. M. (2008). Spontaneous squamous cell carcinoma induced by the somatic inactivation of retinoblastoma and Trp53 tumor suppressors. Cancer Res 68(3), 683-92.

Marur, S., D'Souza, G., Westra, W. H. \& Forastiere, A. A. (2010). HPV-associated head and neck cancer: a virus-related cancer epidemic. Lancet Oncol 11(8), 781-9.

McCance, D. J., Kopan, R., Fuchs, E. \& Laimins, L. A. (1988). Human papillomavirus type 16 alters human epithelial cell differentiation in vitro. Proc Natl Acad Sci U S A 85(19), 7169-73.

Meyers, C., Frattini, M. G., Hudson, J. B. \& Laimins, L. A. (1992). Biosynthesis of human papillomavirus from a continuous cell line upon epithelial differentiation. Science 257(5072), 971-3.

Moral, M., Segrelles, C., Lara, M. F., Martinez-Cruz, A. B., Lorz, C., Santos, M., GarciaEscudero, R., Lu, J., Kiguchi, K., Buitrago, A., Costa, C., Saiz, C., Rodriguez-Peralto, J. L., Martinez-Tello, F. J., Rodriguez-Pinilla, M., Sanchez-Cespedes, M., Garin, M., Grande, T., Bravo, A., DiGiovanni, J. \& Paramio, J. M. (2009). Akt activation synergizes with Trp53 loss in oral epithelium to produce a novel mouse model for head and neck squamous cell carcinoma. Cancer Res 69(3), 1099-108.

Moreno, V., Bosch, F. X., Munoz, N., Meijer, C. J., Shah, K. V., Walboomers, J. M., Herrero, R. \& Franceschi, S. (2002). Effect of oral contraceptives on risk of cervical cancer in women with human papillomavirus infection: the IARC multicentric case-control study. Lancet 359(9312), 1085-92.

Munoz, N., Franceschi, S., Bosetti, C., Moreno, V., Herrero, R., Smith, J. S., Shah, K. V., Meijer, C. J. \& Bosch, F. X. (2002). Role of parity and human papillomavirus in cervical cancer: the IARC multicentric case-control study. Lancet 359(9312), 1093101.

Pfister, H. (2003). Chapter 8: Human papillomavirus and skin cancer. J Natl Cancer Inst Monogr(31), 52-6.

Riley, R. R., Duensing, S., Brake, T., Munger, K., Lambert, P. F. \& Arbeit, J. M. (2003). Dissection of human papillomavirus E6 and E7 function in transgenic mouse models of cervical carcinogenesis. Cancer Res 63(16), 4862-71. 
Ruiz, S., Santos, M., Lara, M. F., Segrelles, C., Ballestin, C. \& Paramio, J. M. (2005). Unexpected roles for $\mathrm{pRb}$ in mouse skin carcinogenesis. Cancer Res 65(21), 9678-86.

Ruiz, S., Santos, M., Segrelles, C., Leis, H., Jorcano, J. L., Berns, A., Paramio, J. M. \& Vooijs, M. (2004). Unique and overlapping functions of pRb and p107 in the control of proliferation and differentiation in epidermis. Development 131(11), 2737-48.

Ruiz, S., Segrelles, C., Bravo, A., Santos, M., Perez, P., Leis, H., Jorcano, J. L. \& Paramio, J. M. (2003). Abnormal epidermal differentiation and impaired epithelial-mesenchymal tissue interactions in mice lacking the retinoblastoma relatives p107 and p130. Development 130(11), 2341-53.

Schaper, I. D., Marcuzzi, G. P., Weissenborn, S. J., Kasper, H. U., Dries, V., Smyth, N., Fuchs, P. \& Pfister, H. (2005). Development of skin tumors in mice transgenic for early genes of human papillomavirus type 8. Cancer Res 65(4), 1394-400.

Segrelles, C., Lu, J., Hammann, B., Santos, M., Moral, M., Cascallana, J. L., Lara, M. F., Rho, O., Carbajal, S., Traag, J., Beltran, L., Martinez-Cruz, A. B., Garcia-Escudero, R., Lorz, C., Ruiz, S., Bravo, A., Paramio, J. M. \& DiGiovanni, J. (2007). Deregulated activity of Akt in epithelial basal cells induces spontaneous tumors and heightened sensitivity to skin carcinogenesis. Cancer Res 67(22), 10879-88.

Shai, A., Pitot, H. C. \& Lambert, P. F. (2008). p53 Loss synergizes with estrogen and papillomaviral oncogenes to induce cervical and breast cancers. Cancer Res 68(8), 2622-31.

Shai, A., Pitot, H. C. \& Lambert, P. F. (2010). E6-associated protein is required for human papillomavirus type 16 E6 to cause cervical cancer in mice. Cancer Res 70(12), 506473.

Shin, M. K., Balsitis, S., Brake, T. \& Lambert, P. F. (2009). Human papillomavirus E7 oncoprotein overrides the tumor suppressor activity of p21Cip1 in cervical carcinogenesis. Cancer Res 69(14), 5656-63.

Smith, P. P., Friedman, C. L., Bryant, E. M. \& McDougall, J. K. (1992). Viral integration and fragile sites in human papillomavirus-immortalized human keratinocyte cell lines. Genes Chromosomes Cancer 5(2), 150-7.

Song, S., Liem, A., Miller, J. A. \& Lambert, P. F. (2000). Human papillomavirus types 16 E6 and E7 contribute differently to carcinogenesis. Virology 267(2), 141-50.

Song, S., Pitot, H. C. \& Lambert, P. F. (1999). The human papillomavirus type 16 E6 gene alone is sufficient to induce carcinomas in transgenic animals. J Virol 73(7), 588793.

Strati, K. \& Lambert, P. F. (2007). Role of Rb-dependent and Rb-independent functions of papillomavirus E7 oncogene in head and neck cancer. Cancer Res 67(24), 11585-93.

Strati, K., Pitot, H. C. \& Lambert, P. F. (2006). Identification of biomarkers that distinguish human papillomavirus (HPV)-positive versus HPV-negative head and neck cancers in a mouse model. Proc Natl Acad Sci U S A 103(38), 14152-7.

Wang, H. K., Duffy, A. A., Broker, T. R. \& Chow, L. T. (2009). Robust production and passaging of infectious HPV in squamous epithelium of primary human keratinocytes. Genes Dev 23(2), 181-94.

Werness, B. A., Levine, A. J. \& Howley, P. M. (1990). Association of human papillomavirus types 16 and 18 E6 proteins with p53. Science 248(4951), 76-9.

Woodworth, C. D., Cheng, S., Simpson, S., Hamacher, L., Chow, L. T., Broker, T. R. \& DiPaolo, J. A. (1992). Recombinant retroviruses encoding human papillomavirus 
type 18 E6 and E7 genes stimulate proliferation and delay differentiation of human keratinocytes early after infection. Oncogene 7(4), 619-26. zur Hausen, H. (2002). Papillomaviruses and cancer: from basic studies to clinical application. Nat Rev Cancer 2(5), 342-50. 


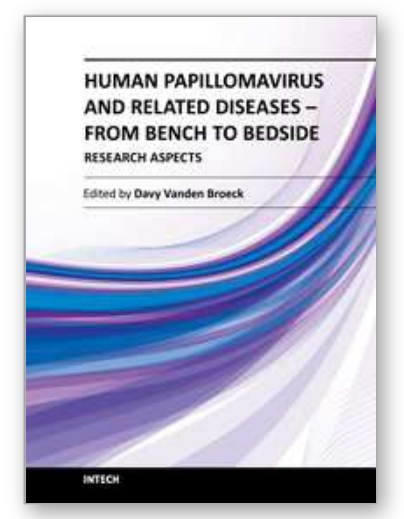

\author{
Human Papillomavirus and Related Diseases - From Bench to \\ Bedside - Research aspects \\ Edited by Dr. Davy Vanden Broeck
}

ISBN 978-953-307-855-7

Hard cover, 406 pages

Publisher InTech

Published online 25, January, 2012

Published in print edition January, 2012

Cervical cancer is the second most prevalent cancer among women worldwide, and infection with Human Papilloma Virus (HPV) has been identified as the causal agent for this condition. The natural history of cervical cancer is characterized by slow disease progression, rendering the condition, in essence, preventable and even treatable when diagnosed in early stages. Pap smear and the recently introduced prophylactic vaccines are the most prominent prevention options, but despite the availability of these primary and secondary screening tools, the global burden of disease is unfortunately still very high. This book will focus on epidemiological and fundamental research aspects in the area of HPV, and it will update those working in this fast-progressing field with the latest information.

\title{
How to reference
}

In order to correctly reference this scholarly work, feel free to copy and paste the following:

Águeda Buitrago-Pérez, Jesús M. Paramio and Ramón García-Escudero (2012). Analysis Models for HPVRelated Pathobiology, Human Papillomavirus and Related Diseases - From Bench to Bedside - Research aspects, Dr. Davy Vanden Broeck (Ed.), ISBN: 978-953-307-855-7, InTech, Available from: http://www.intechopen.com/books/human-papillomavirus-and-related-diseases-from-bench-to-bedsideresearch-aspects/analysis-models-for-hpv-related-pathobiology

\section{INTECH}

open science | open minds

\author{
InTech Europe \\ University Campus STeP Ri \\ Slavka Krautzeka 83/A \\ 51000 Rijeka, Croatia \\ Phone: +385 (51) 770447 \\ Fax: +385 (51) 686166 \\ www.intechopen.com
}

\author{
InTech China \\ Unit 405, Office Block, Hotel Equatorial Shanghai \\ No.65, Yan An Road (West), Shanghai, 200040, China \\ 中国上海市延安西路65号上海国际贵都大饭店办公楼 405 单元 \\ Phone: +86-21-62489820 \\ Fax: $+86-21-62489821$
}


(C) 2012 The Author(s). Licensee IntechOpen. This is an open access article distributed under the terms of the Creative Commons Attribution 3.0 License, which permits unrestricted use, distribution, and reproduction in any medium, provided the original work is properly cited. 